\title{
Reform and exploration of Independent college computer specialty personnel training mode
}

\author{
Yi-zhuo Guo ${ }^{1}$ Xiaofeng $\mathrm{Li}^{2}$ \\ 1 Department of Computer Science and Technology, Cheng-Dong College of Northeast Agricultural \\ University, Harbin 150025, China \\ gssg289@yahoo.com.cn
}

2 Department of Informatics and Science, Heilongjiang International University, Harbin 150025, China

mberse@126.com

keywords: independent college; Personnel training mode; Quality education; School-enterprise cooperation

\begin{abstract}
This article is aimed at the mode of existence of curriculum system similar to computer talents straining independent school, the teachers strength is weak, professional knowledge lag, lack of practical problems in practice, based on the school-enterprise cooperation "Cheng-dong college years trying $3+1 "$ personnel training mode, the computer professional positining of personnel training, improve the echelon construction of teachers, curriculum system construction training base, personnel training and other aspects of reform. Strengthening the cultivation of students' ability, ensure that the employability and competitiveness of students, but also to strengthen college ability.

Introduction

With the rapid development of science and technology, society has entered the digital age. The global information technology, computers in people's minds has already removed the strange and mysterious "veil", it has been widely applied to every field of people's life, social demand for computer professionals have been increased, at the same time the computer professional also obtained the fast development. In 2020 China will become the big country of human resources, to achieve this grand goal, we must pay attention to the quality of talent. As the main position of talent cultivation in Colleges and universities, should mobilize all resources, the use of various means, to carry out a full range of education and training of students. Reform and exploration of the mode of talents cultivation of independent college is the base and key to improve the quality of education, to solve this problem to improve the overall quality of the far-reaching significance of higher education in china. ${ }^{[1,2]}$
\end{abstract}

\section{Analysis about the positioning of talent training}

Methods the advantages and disadvantages of ordinary higher school

Higher education for the elite education, the development of strong theory to research direction. Most schools have a long history, profound educational background, strong teachers strength and rich resources, but it is also faced with the impact of the expansion, facing the elite education into mass personalization education issues, the high standards have many years of accumulated running mode and personnel training mode are similar the theory and practice of closely linked, not enough. B. Personnel positioning and analysis of Independent College

The Independent College of personnel training and personnel management of higher school pressure greater than ordinary. We are faced with a group of students in Colleges and universities is still lower than two scores 100 points or so, not the same as the starting point, but the end is same, have to cultivate qualified graduates can get recognized by the market, enterprises need. Figure 1 for the years 2008 --2013 in Heilongjiang college entrance admission: 


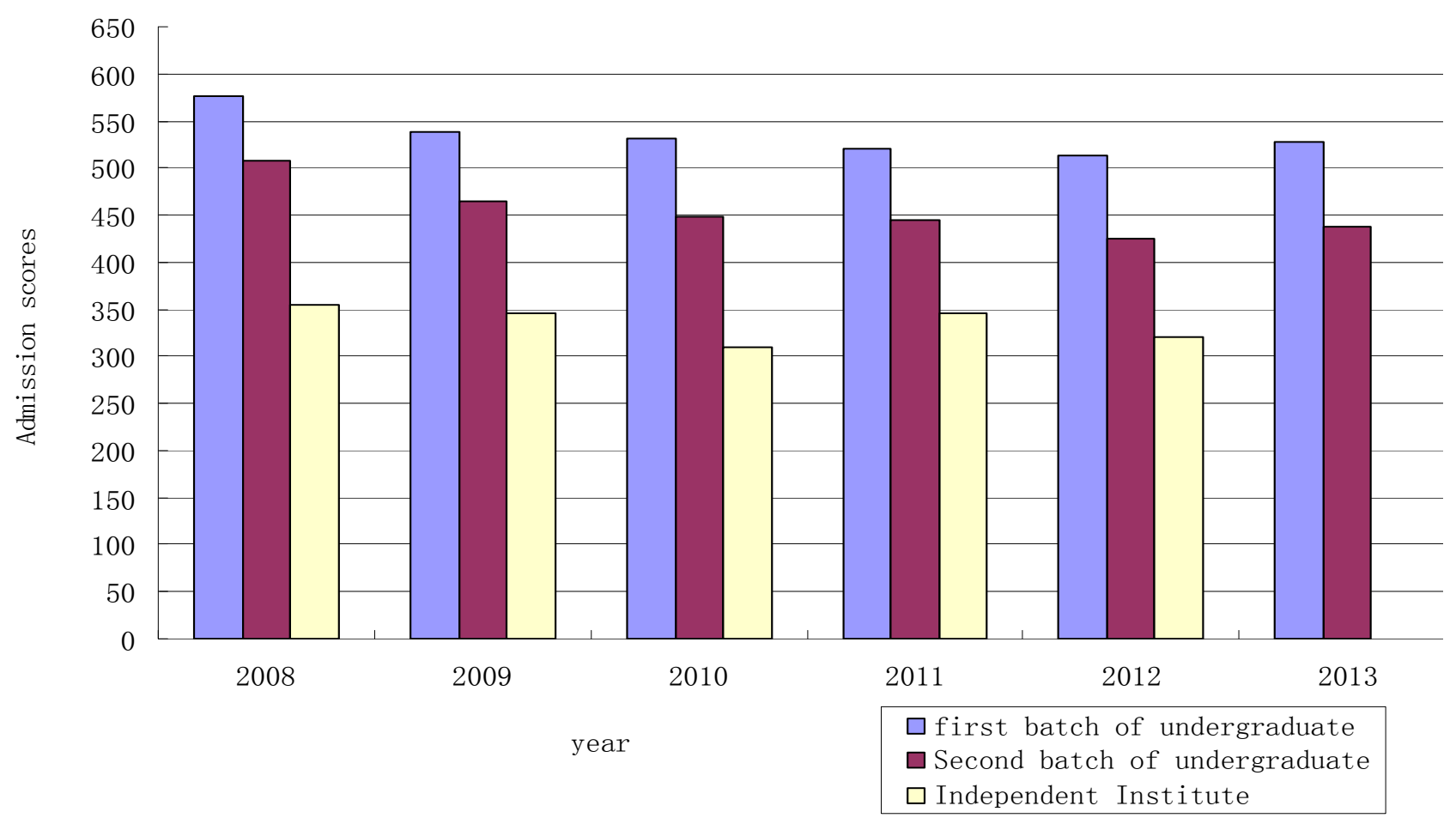

figure1 Heilongjiang 2008-2013 science exam admission

Independent college first clear orientation, to cultivate applied talents with professional skills and computer software development and information technology. Now the software outsourcing business volume increase, software talent shortage of talent structure is not balanced. The current lack of a large number of be engaged in the basic work of the "software blue collar", this is our way of positioning of the independent college. Elite education focus on thick foundation and wide adaptability, the popular education emphasized the characteristics and adaptability, emphasize the importance of training schools and professional more accurate positioning. Different types of school students in the cultivation of knowledge and ability should be a certain gap, according to the different cultivation objectives, using different teaching strategies, planning and provide different teaching content, to improve the teaching level of professional education. ${ }^{[3]}$

\section{The reform and innovation of the personnel training mode Improve teachers team construction}

To cultivate outstanding talents, the premise is to have good teachers do foundation. In view of the independent college teachers, teachers' teaching enthusiasm more than the actual problem is lack of experience. Northeast Agricultural University, college to College Department of computer application hired professional ability, has the rich experience of the old professor of teaching and scientific research as a leader, quality in teaching, for the young teachers in scientific research work direction. To encourage young teachers to continue their studies, school learning opportunities, to cooperative enterprises to participate in the training, to participate in professional computer forum, to strengthen and improve the construction of research team, strengthen the construction of teachers' team.

First of all, to attract talents to join in our education team. Perfect and improve every teacher teaching level and scientific research ability, to make the ability of teachers, education and professional title are improved to strengthen teachers structure rationalization. Secondly, the establishment of teaching team in the research direction of every teacher, and actively organize the teaching team construction, declare actively organize various teaching team, curriculum and research project, give full play to the ability of each, echelon construction with both old and new, let the young strength of rapid growth, the formation of a certain scale of scientific research team. Thirdly, to strengthen the training of teachers' practical ability, striving to be the "Double Teachers", pay attention to enterprise practical experience of the project manager to participate in the study, 
between the school and the school of communication and IT training class, holiday business learning, teaching activities; finally, to establish a reasonable teaching appraisal system, scientific research and award assessment system, inspire the enthusiasm of teachers, improve the teaching and research level. Through these measures, the Department of 37 full-time teachers, lecturers and over 95\% titles, has formed the Department 2, 4 scientific research team, research projects have been related to the provincial and national level, academic papers published more than 50 articles, EI retrieval has nearly 20 more, teaching ability has been obviously, this is not only the development of the school is very big also played an important role in teaching. ${ }^{[4]}$

\section{Market analysis of school-enterprise cooperation to improve the teaching course system}

Computer professional development of independent college more than ten years, mostly in accordance with the curriculum system in college professional training program setting, curriculum setting are identical, curriculum theory is strong, but because of the characteristics of computer professional development speed, curriculum design from the social reality of need, the content is too general, lack of practical problems. To cultivate talents employment is difficult, but there is lack of corporate recruiters, important problems of this phenomenon in every university thinking. To talent cultivation plan reasonable revision, qualified personnel output.

If the school talent understanding for the school production out of the "products", how can we let us create "products" become popular. The school can not work behind closed doors, imagination. We should research the market, to truly understand what needs the enterprise, make we tailored for the enterprise, that is to solve two problems of the talent employment and enterprise unmanned by school culture.

In recent years, college into the school-enterprise cooperation mode, especially the computer system, training mode is used to try and improve the "3+1" mode, has become a mature. Beida Jadebird, Dalian Huaxin, Haikang software, Danei technology, China National Software \& Service Co.,LTD. other enterprises, has signed a cooperation agreement with me. Practice as a basis for students of the carrier, is the student to contact the society, culture and the important place to improve practical skills and good ability, which is a strong supplement to school education. ${ }^{[5]}$

These enterprises have their own training based, they have a good business reputation, has a certain scale and a clear direction of development, have fixed development projects, but also has rich experience in enterprise training teacher and years with experience of the team project manager. The main courses of colleges and enterprises are set according to the practical experience and characteristics of enterprises. Last year to go directly to the enterprise practice, not only to put the knowledge into full play in the workplace, but also understand the business documents, employing standard enterprise, by the students into the transition of professional and technical personnel.

Cheng-dong college Computer professional "3+1" school-enterprise cooperation mode , Can reach more than $95 \%$ in recent years, the employment rate of graduates, most of the employment or software company, figure 2 is 2012-2013 years the employment situation of graduates:

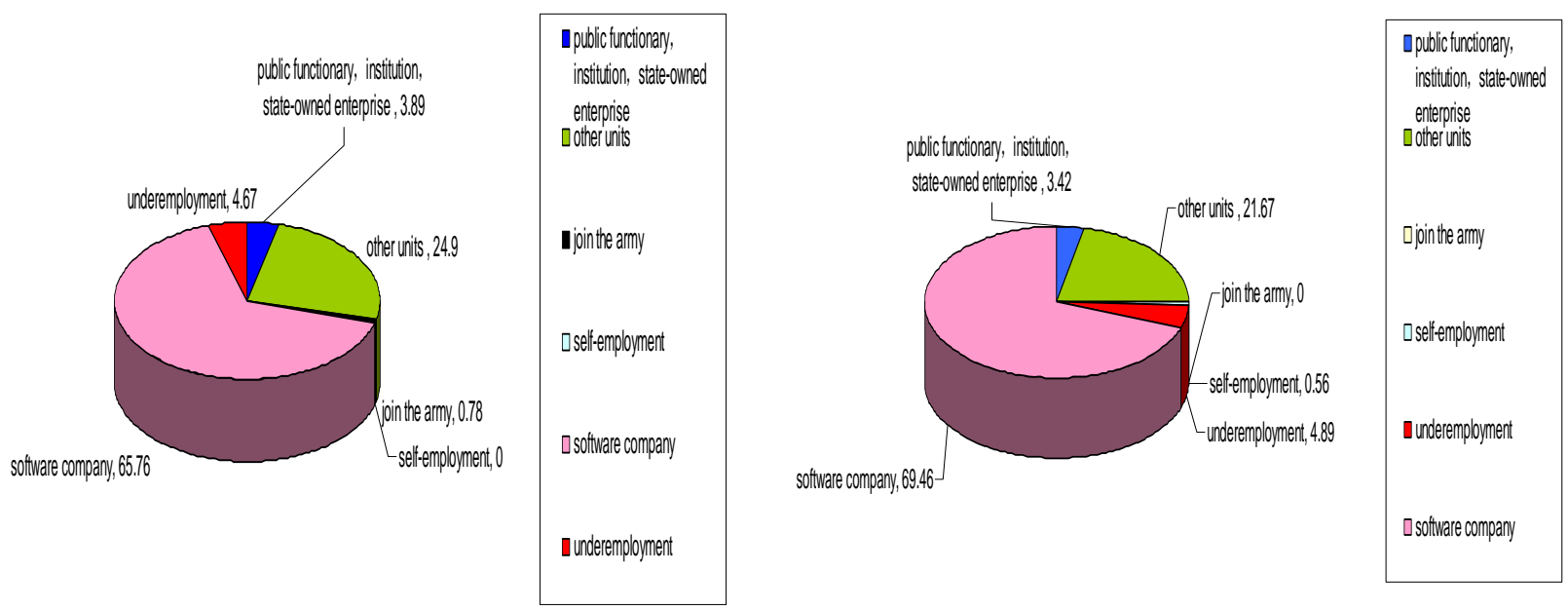

Figure2 2012-2013 year The employment situation of graduates 


\section{Conclusions}

Northeast Agricultural University, College of computer talents training in the reform, the overall quality of teachers, improve teaching quality. Through the formation of school-enterprise cooperation teaching practice has achieved fruitful results, graduates employment with security. In personnel training, we will be in the teaching environment construction, perfect the curriculum system, the construction of teachers' team, the school-enterprise cooperation links strengthen research, try to finish the teaching reform of computer application talents in short time goal, hoped to have the certain reference and demonstration training computer talents in independent colleges.

\section{References}

[1] Chen zhenqing, Tan xiaodong, Luo lanhua, Liu lanqing. Analysis and Countermeasures of cultivation mode of talents of computer specialty in Local Universities. Computer Education 2012

[2] Liu lun The ability of computer application talents in research and practice of teaching reform. Computer Education 2013

[3] Zhang guoyin,Liu haibuo, Shen jing. Exploration and practice of the training mode of computer professionals. Computer Education 2008

[4] Yu yonghong, Study of characteristics of local colleges and universities, the adaptability of computer professional talent training. Journal of Huaibei Vocational and Technical College.2010

[5] Wang zhongmin, Wang jihai, Hang jungang Discussion on the personnel training mode of professional colleges and universities computer industry. Computer Education 2010 